\title{
REVIEW
}

\section{Systematic review and meta-analysis: pharmacogenetics of anti-TNF treatment response in rheumatoid arthritis}

\author{
S Bek ${ }^{1}$, AB Bojesen ${ }^{1,2}$, JV Nielsen ${ }^{1}$, J Sode ${ }^{1}$, S Bank ${ }^{1}$, U Vogel $^{2,3}$ and V Andersen ${ }^{1,4,5,6}$
}

\begin{abstract}
Rheumatoid arthritis (RA) is a chronic inflammatory disease that affects $\sim 1 \%$ of the Caucasian population. Over the last decades, the availability of biological drugs targeting the proinflammatory cytokine tumour necrosis factor a, anti-TNF drugs, has improved the treatment of patients with RA. However, one-third of the patients do not respond to the treatment. We wanted to evaluate the status of pharmacogenomics of anti-TNF treatment. We performed a PubMed literature search and all studies reporting original data on associations between genetic variants and anti-TNF treatment response in RA patients were included and results evaluated by meta-analysis. In total, 25 single nucleotide polymorphisms were found to be associated with anti-TNF treatment response in RA (19 from genome-wide association studies and 6 from the meta-analyses), and these map to genes involved in T cell function, NFKB and TNF signalling pathways (including CTCN5, TEC, PTPRC, FCGR2A, NFKBIB, FCGR2A, IRAK3). Explorative prediction analyses found that biomarkers for clinical treatment selection are not yet available.
\end{abstract}

The Pharmacogenomics Journal (2017) 17, 403-411; doi:10.1038/tpj.2017.26; published online 13 June 2017

\section{INTRODUCTION}

Rheumatoid arthritis (RA) is a chronic inflammatory disease that affects $\sim 1 \%$ of the Caucasian population. ${ }^{1}$ Disease onset typically manifests at age of 35-50 years, and females are affected 2.5 times more frequently than males. RA is characterised by synovial inflammation of joints most often affecting the joints of hands, wrist and feet, potentially leading to joint destruction, and functional disability. Furthermore, extra-articular manifestations may occur, for example, osteoporosis, vasculitis or interstitial lung disease. The manifestations are consequences of a chronically activated immune system. Both proinflammatory cytokines as tumour necrosis factor (TNF), interleukin (IL)-6, IL-8, GM-CSF, IL-1 and anti-inflammatory cytokines as IL-10 are involved. TNFa is a member of the TNF family of regulators of immune and inflammatory responses, which may also mediate cell death. ${ }^{2}$

In the 1980s, it was shown that TNFa has a prominent role in $\mathrm{RA}^{3-5}$ and over the past decades, the availability of drugs targeting tumour necrosis factor a (anti-TNF) has improved the treatment of RA patients. Nevertheless, only $60-70 \%$ of patients have a good to moderate response to the anti-TNF treatment, whereas $30-40 \%$ have no or insufficient response. 2,6 Apart from anti-TNF drugs, biological compounds targeting CD20, T-lymphocyte antigen 4 immunoglobulin, interleukin 6 receptor and B-cells have been developed. ${ }^{7,8}$ Until now, the treatment paradigm has been 'one drug suits all'. Thereby, patients may remain in high disease activity, with irreversible joint damage as a possible consequence. Pharmacogenetics may identify the individual patient's signature that may help guide the treatment selection (reviewed in refs 9,10). Genetic variants may impact anti-TNF drug response. ${ }^{9-16}$ They may therefore be utilised as biomarkers for treatment selection by stratifying patients according to the expected response following medical treatment. Furthermore, genetic biomarkers hold the advantage that they do not change over time.

Biomarkers able to predict treatment response will help optimising treatment, reduce adverse side-effects and avoid treatment with drugs without effect in the individual patients. In addition, such biomarkers will also help improving the use of health care resources. The expectations from patients, health care professionals and health authorities are high. 'Personalised medicine represents one of the most innovative new concepts in health care. It holds real promise for more effective early diagnosis and more effective and less toxic treatments for patients, for improved medical service to citizens, and for improving the overall health of the population' (http://permed2020.eu/., 2015). 'Personalised medicine refers to a medical model using characterisation of individual's phenotypes and genotypes (for example, molecular profiling, medical imaging, lifestyle data) for tailoring the right therapeutic strategy for the right person at the right time, and/or to determine the predisposition to disease and/or to deliver timely and targeted prevention' (http://permed2020.eu/., 2015). Until now, most advances in applied pharmacogenetics have taken place in the field of anticancer therapy. ${ }^{17}$

Thus, we undertook to review case-control studies on genetic variants associated with anti-TNF treatment response in RA patients.

\section{MATERIALS AND METHODS}

A systematic review and meta-analysis were carried out according to the guidelines of 'Preferred Reporting Items for Systematic

\footnotetext{
${ }^{1}$ Focused Research Unit for Molecular Diagnostic and Clinical Research, IRS-Center Sonderjylland, Laboratory Center, Hospital of Southern Jutland, Aabenraa, Denmark; ${ }^{2}$ Research Unit for E-mental Health, Mental Health Services in the Region of Southern Odense, Odense, Denmark; ${ }^{3}$ National Research Centre for the Working Environment, Copenhagen, Denmark; ${ }^{4}$ Institute of Molecular Medicine, University of Southern Denmark, Odense, Denmark; ${ }^{5}$ Institute of Regional Health Research, University of Southern Denmark, Odense, Denmark and ${ }^{6}$ Odense Patient Data Explorative Network, Odense University Hospital, Odense, Denmark. Correspondence: Professor V Andersen, Focused Research Unit for Molecular Diagnostic and Clinical Research, IRS-Center Sonderjylland, Laboratory Center, Hospital of Southern Jutland, Kresten Philipsens Vej 15, Aabenraa 6200, Denmark. E-mail: Vibeke.Andersen1@rsyd.dk

Received 22 November 2016; revised 8 February 2017; accepted 2 March 2017; published online 13 June 2017
} 


\section{PRISMA 2009 Flow Diagram}

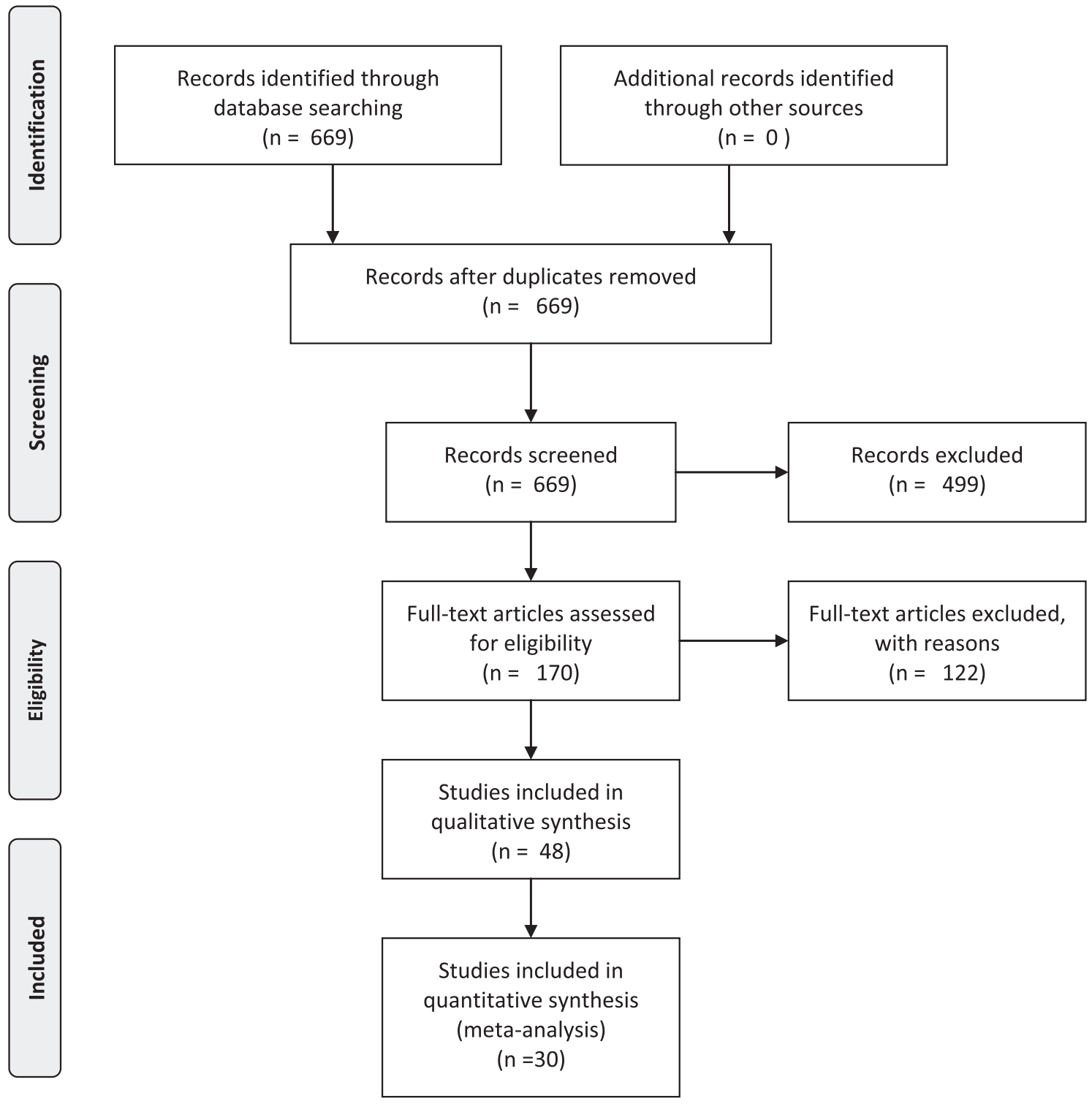

Figure 1. Flow diagram of included studies.

Reviews and Meta-Analyses' (PRISMA) statement. ${ }^{18}$ Three individual searches were performed in PubMed combining various alternative search terms for (1) 'anti-TNF treatment', (2) 'genetic variation' and (3) 'autoimmune disease', respectively, resulting in 669 abstracts (latest search date: 29th of August 2016). A full list of search terms is found in Supplementary Table 1. Figure 1 shows the flow diagram of included studies. All studies suggesting that they presented original data on associations between polymorphisms and anti-TNF treatment response in autoimmune diseases were retrieved (170 articles) and reviewed by three independent authors (SiB, JVN, VA). Exclusion criteria were: $<100$ cases available for treatment evaluation, missing data on treatment response, not reporting original data and not reporting data on anti-TNF response in RA (122 studies). In total, 47 studies reported association between genetic markers and anti-TNF response in RA. No further studies were identified by searching the literature list of the retrieved articles. Data on study design, number of patients, response criteria, odds ratios (OR) and 95\% confidence intervals $(95 \% \mathrm{Cl})$ or numbers of good responders, moderate and nonresponders, and genotypes were included.

\section{Statistics}

Meta-analysis was performed on studies using EULAR response criteria. ${ }^{19}$ All polymorphisms studied in at least two studies (with a minimum of one significant association with response), and where data on genotypes and treatment response could be retrieved, were included in a meta-analysis (30 studies). The meta-analysis was based on the total number of patients in the cohorts. 


\begin{tabular}{|c|c|c|c|c|c|c|c|c|}
\hline Disease & Ethnicity/country & Biological drug(s) & $D M A R D s^{\mathrm{a}}(\%)$ & $M T X^{\mathrm{a}}(\%)$ & Response criteria bases on & Response evaluated after & $\mathrm{N}$ cases & Refs. \\
\hline \multicolumn{9}{|c|}{ Candidate } \\
\hline RA & Caucasian, Spain & INX/ADM/ETC & 100 & 57.7 & ACR/EULAR & & 1239 & Canet et al. ${ }^{29}$ \\
\hline RA & Caucasian, UK & INX/ADM/ETC & 81.8 & - & $\mathrm{EULAR}^{\mathrm{b}} / \Delta \mathrm{DAS} 28^{\mathrm{b}}$ & 3-6 months & 1750 & Smith et al. ${ }^{23}$ \\
\hline RA & Denmark & INX/ADM/ETC & 84 & 73 & EULAR $^{c}$ & 3-6 months & 1007 & Sode et al. ${ }^{15}$ \\
\hline RA & Denmark & INX/ADM/ETC & 83 & 72 & EULAR $^{c}$ & 3-6 months & 469 & Sode et $a l^{15}$ \\
\hline RA & Caucasian, Poland & INX/ADM/ETC & - & 93 & $\mathrm{EULAR}^{\mathrm{C}} / \Delta \mathrm{DAS} 28^{\mathrm{d}}$ & 12 and 24 weeks & 284 & Iwaszko et al. ${ }^{24}$ \\
\hline RA & Denmark & INX/ADM/ETC & 84 & - & EULAR & 2-6 months & 538 & Sode et al. ${ }^{16}$ \\
\hline RA & Caucasian, Poland & INX/ADM/ETC & - & 92 & $\mathrm{EULAR}^{\mathrm{C}} / \Delta \mathrm{DAS} 28^{\mathrm{d}}$ & 12 and 24 weeks & 223 & Iwaszko et al. ${ }^{21}$ \\
\hline RA & Spain and Greece & INX/ADM/ETC & 95 & - & $\mathrm{EULAR}^{\mathrm{C}} / \triangle \mathrm{DAS} 28$ & 3 and 6 months & 755 & Ferreiro-Iglesias et al. ${ }^{28}$ \\
\hline RA & Multicenter ${ }^{\mathrm{e}}$ & INX/ADM/ETC & - & 86.2 & EULAR $^{c}$ & 6 months & 471 & Canet et al. ${ }^{22}$ \\
\hline RA & Portugal & INX/ADM/ETC & 91.8 & 82.2 & $\mathrm{EULAR}^{f} / \Delta \mathrm{DAS} 28$ & 6 months & 383 & Canhão et al. ${ }^{58}$ \\
\hline RA & The Netherland & ADM & - & 82.1 & $\mathrm{EULAR}^{\mathrm{g}} / \Delta \mathrm{DAS} 28$ & 14 weeks & 302 & Dávila-Fajardo et al. ${ }^{32}$ \\
\hline RA & Spain and Greece & INX/ADM/ETC & 94.6 & - & EULAR/ $\triangle D A S 28$ & 3,6 and 12 months & 423 & Montes et al. ${ }^{33}$ \\
\hline RA & Poland & INX/ADM/ETC & - & 92.5 & $\mathrm{EULAR}^{\mathrm{h}} / \Delta \mathrm{DAS} 28$ & 6 months & 280 & Swierkot et al. ${ }^{52}$ \\
\hline RA & Denmark & INX/ADM/ETC & 84.2 & - & EULAR'/ACR50 & $3-6$ months & 538 & Sode et al. ${ }^{14}$ \\
\hline RA & Spain and Greece & INX/ADM/ETC & 88.4 & - & EULAR $^{c} / \Delta$ DAS28 & 3,6 and 12 months & 410 & Montes et al..$^{56}$ \\
\hline RA & Spanish & INX/ADM/ETC & & & EULAR/ $\Delta \mathrm{DAS} 28$ & 6 and 12 months & 419 & Márquez et al. ${ }^{25}$ \\
\hline RA & Spanish & INX/ADM/ETC & & & EULAR/DDAS28 & 6 and 12 months & 134 & Márquez et al. ${ }^{25}$ \\
\hline RA & Japan & INX/ADM/ETC & 28.7 & 89.1 & $\mathrm{EULAR}^{\mathrm{c}} / \triangle \mathrm{DAS} 28$ & 24 weeks & 101 & Nishimoto et al. ${ }^{31}$ \\
\hline RA & Spain & INX/ADM/ETC & 78.9 & & EULAR $^{c}$ & $6,12,18$ and 24 months & 199 & Dávila-Fajardo et al. ${ }^{31}$ \\
\hline RA & Greece & INX/ADM/ETC & - & - & $\mathrm{EULAR}^{\mathrm{c}} / \triangle \mathrm{DAS} 28$ & 6 months & 183 & ${\text { Zervou et } a l^{55}}^{5}$ \\
\hline RA & United Kingdom & INX/ADM/ETC & - & - & EULAR $^{\mathrm{c}, ~} \mathrm{~g} / \Delta \mathrm{DAS} 28$ & 6 months & 1278 & Mathews et al. $^{44}$ \\
\hline RA & Spain & INX/ADM/ETC & - & - & $\mathrm{EULAR}^{\mathrm{g}} / \Delta \mathrm{DAS} 28^{\mathrm{d}}$ & 12 weeks & 315 & Acosta-Colman et al. ${ }^{59}$ \\
\hline RA & Italy & ADM & - & - & EULAR & 12 weeks & 377 & Ceccarelli et al. ${ }^{30}$ \\
\hline RA & United Kingdom & INX/ADM/ETC & 73 & - & EULAR $^{\mathrm{g}} / \Delta \mathrm{DAS}^{2} 8^{\mathrm{d}}$ & 6 months & 1115 & Plant et $a .^{47}$ \\
\hline RA & The Netherland & INX/ADM & - & 61.0 & EULAR $^{i}$ & 3 months & 182 & Coenen et al. $^{38}$ \\
\hline RA & Sweden & ADM/ETC & - & 68.8 & EULAR $^{\mathrm{i}}$ & 3 months & 269 & Coenen et $a l^{38}$ \\
\hline RA & United Kingdom & INX/ADM/ETC & 68 & - & $\Delta \mathrm{DAS} 28$ and EULAR ${ }^{\mathrm{C}}$ & 6 months & 1102 & Coulthard et al. ${ }^{39}$ \\
\hline RA & United Kingdom & INX/ADM/ETC & 72 & - & $\triangle \mathrm{DAS} 28$ and EULAR ${ }^{\mathrm{C}}$ & 6 months & 909 & Potter et $a l^{48}$ \\
\hline RA & United Kingdom & INX/ADM/ETC & 72.7 & - & $\triangle \mathrm{DAS} 28$ and EULAR ${ }^{\mathrm{f}}$ & 6 months & 1334 & Tan et al. ${ }^{53}$ \\
\hline RA & Spain & INX/ADM/ETC & - & - & EULAR $^{\mathrm{f}} / \triangle \mathrm{DAS} 28^{\mathrm{j}}$ & 3 months & 151 & Suarez-Gestal et al. ${ }^{51}$ \\
\hline RA & Multi-cohorts $^{\mathrm{k}}$ & INX/ADM/ETC & - & $0-100$ & EULAR $^{9} / \Delta$ DAS 28 & $3-12$ months & 1283 & Cui et $a l^{40}$ \\
\hline RA & United Kingdom & INX/ADM/ETC & - & - & $\triangle \mathrm{DAS} 28$ & 6 months & 602 & Potter et al. ${ }^{36}$ \\
\hline RA & Caucasian & INX/ADM/ETC & - & - & $\mathrm{EULAR}^{\mathrm{i}} / \triangle \mathrm{DAS} 28$ & 6 months & 1050 & Hassan et al. ${ }^{41}$ \\
\hline RA & United Kingdom & INX/ADM/ETC & 73 & - & $\Delta \mathrm{DAS} 28$ & 6 months & 624 & Bowes et al. ${ }^{26}$ \\
\hline RA & United Kingdom & INX/ADM/ETC & 68 & - & $\triangle \mathrm{DAS} 28$ & 6 months & 411 & Bowes et al. ${ }^{26}$ \\
\hline RA & United Kingdom & INX/ADM/ETC & 69 & - & $\mathrm{EULAR}^{\mathrm{g}} / \triangle \mathrm{DAS} 28$ & 6 months & 1050 & Maxwell et al. ${ }^{57}$ \\
\hline RA & The Netherland & INX/ADM & - & - & $\Delta \mathrm{DAS} 28$ & 3 and 6 months & 234 & Toonen et al. ${ }^{54}$ \\
\hline RA & United Kingdom & INX/ADM/ETC & 73 & - & $\triangle \mathrm{DAS} 28$ & 6 months & 642 & Potter et al. ${ }^{49}$ \\
\hline RA & Italy & INX/ADM/ETC & - & - & $\triangle \mathrm{DAS} 28 / \mathrm{ACR} 20 / 50 / 70^{\prime}$ & 12 months & 105 & Ongaro et al. $^{45}$ \\
\hline RA & Spain & INX & - & - & $\Delta \mathrm{DAS} 28^{\mathrm{d}}$ & 30 weeks & 113 & Pinto et al..$^{35}$ \\
\hline RA & France & ADM & 72 & 47 & $A C R 50^{\mathrm{m}}$ & 12 weeks & 388 & Miceli-Richard et al. ${ }^{27}$ \\
\hline JIA & Caucasian & INX/ADM/ETC & & & ACR Pedi 30 & 3 months & 107 & Cimaz et al. ${ }^{37}$ \\
\hline RA & Sweden & INX/ ETC & - & - & EULAR/ACR20/50/70' & 3 months & 282 & Kastbom et al. ${ }^{42}$ \\
\hline JIA & Caucasian & ETC & - & - & ACR-JRA $30^{n}$ & 3 months & 137 & Schmeling et al. ${ }^{50}$ \\
\hline RA & France & INX & - & - & $A R C 20^{\circ}$ & 30 weeks & 198 & Marotte et al. ${ }^{43}$ \\
\hline RA & Sweden & ETC & - & - & ARC $20^{\circ} / \triangle \mathrm{DAS} 28$ & 3 months & 123 & Padyukov et al. ${ }^{46}$ \\
\hline \multicolumn{9}{|l|}{ GWAS } \\
\hline RA & Japanese & INX/ADM/ETC & - & - & $\Delta$ DAS28 & 3 and 6 months & 444 & Honne et al. ${ }^{60}$ \\
\hline RA & Spanish & INX/ADM/ETC & - & - & EULAR & 12 weeks & 361 & Julià et $a l^{61}$ \\
\hline RA & Dutch & INX/ADM/ETC & - & - & $\triangle \mathrm{DAS} 28$ & 3 months & 984 & Umicevic et.al. ${ }^{64}$ \\
\hline
\end{tabular}


Table 1. (Continued)

\begin{tabular}{|c|c|c|c|c|c|c|c|c|}
\hline Disease & Ethnicity/country & Biological drug(s) & DMARDs ${ }^{\mathrm{a}}(\%)$ & $M T X^{\mathrm{a}}(\%)$ & Response criteria bases on & Response evaluated after & $\mathrm{N}$ cases & Refs. \\
\hline RA & Danish & INX/ADM/ETC & - & - & EULAR/DDAS28 & 14 weeks & 196 & Krintel et al. ${ }^{62}$ \\
\hline RA & Great Britain & INX/ADM/ETC & - & - & $\Delta$ DAS2 $8^{\mathrm{p}}$ & 6 months & 566 & Plant et al..$^{63}$ \\
\hline
\end{tabular}

Abbreviations: ACR, American College of Rheumatology outcome measure \% improvement; ADM, adalimumab; DAS28, disease activity score for 28 joints; DMARDs, disease-modifying antirheumatic drugs; ETC, etanercept; EULAR, European League Against Rheumatism; INX, inflixiamb; JIA, juvenile idiopathic arthritis; MTX, methotrexate; RA, rheumatoid arthritis, ${ }^{\mathrm{a}}$ Treatment with additional drugs during biological

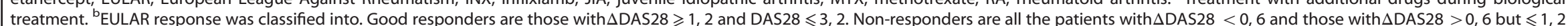
and DAS28 $>5,1$. All the remaining patients are moderate responders. ${ }^{C}$ EULAR response were defined as good and moderate response. ${ }^{\mathrm{d}}$ Good responders are those with $\triangle D A S 28 \geqslant 1,2$ and DAS28 $\leqslant 3,2$. Non-

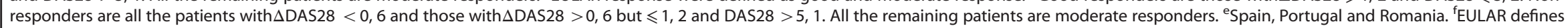
anti-TNF response in three categories: good, moderate and non-response-moderate response were removed and good versus non-response were analysed. ${ }^{9}$ EULAR response were defined as good response. ${ }^{h}$ EULAR response were defined as remission and low disease activity. ${ }^{\mathrm{i} E U L A R}$ response were not specific defined as seen in refs 6 and $7 .{ }^{\mathrm{j}}$ Anti-TNF response was evaluated by absolute ( $\left.\triangle \mathrm{DAS} 28\right)$ and relative ( $\triangle$ DAS28/DAS28 baseline) DAS28 score change. ${ }^{\mathrm{k} A B C o N}(n=116)$, AMC $(n=157)$, BeSt $(n=126)$, BRAGGSS $(n=81)$ BRASS $(n=55)$ EIRA $(n=291)$, ERA $(n=218)$, KI $(n=163)$, JBI $(n=76)$. 'ARC20, 50 and 70 responses is defined if the patients have 20,50 or $70 \%$ improvement in tender and swollen joints, respectively. Patients with ACR20, 50 or 70 response were considered low-, medium and high responders, respectively. ${ }^{m}$ ARC50 is defined as responder if $20 \%$ improvement in tender and swollen joints were achieved as well as a $50 \%$ improvement in at least three of the five criteria: Patients assessment, physician assessment, pain scale, disability/functional questionnaire and acute phase reactant (erythrocyte sedimentation rate or C-reactive protein (CRP)). ${ }^{\mathrm{n}} \mathrm{ARC}-\mathrm{JRA} 30$ is defined as responder if $30 \%$ improvement in tender and swollen joints were achieved as well as a $30 \%$ improvement in at least three of the five criteria: Patients assessment, physician assessment, pain scale, disability/functional questionnaire and acute phase reactant (erythrocyte sedimentation rate or CRP). ${ }^{\circ}$ ARC20 is defined as responder if $20 \%$ improvement in tender and swollen joints were achieved as well as a $20 \%$ improvement in at least three of the five criteria: Patients assessment, physician assessment, pain scale, disability/functional questionnaire and acute phase reactant (erythrocyte sedimentation rate or CRP). ${ }^{\mathrm{P}}$ Anti-TNF response was evaluated by absolute ( $\triangle \mathrm{DAS} 28)$ and relative ( $\left.\triangle \mathrm{DAS} 28 / \mathrm{DAS} 28_{\text {baseline }}\right)$ DAS28 score change.

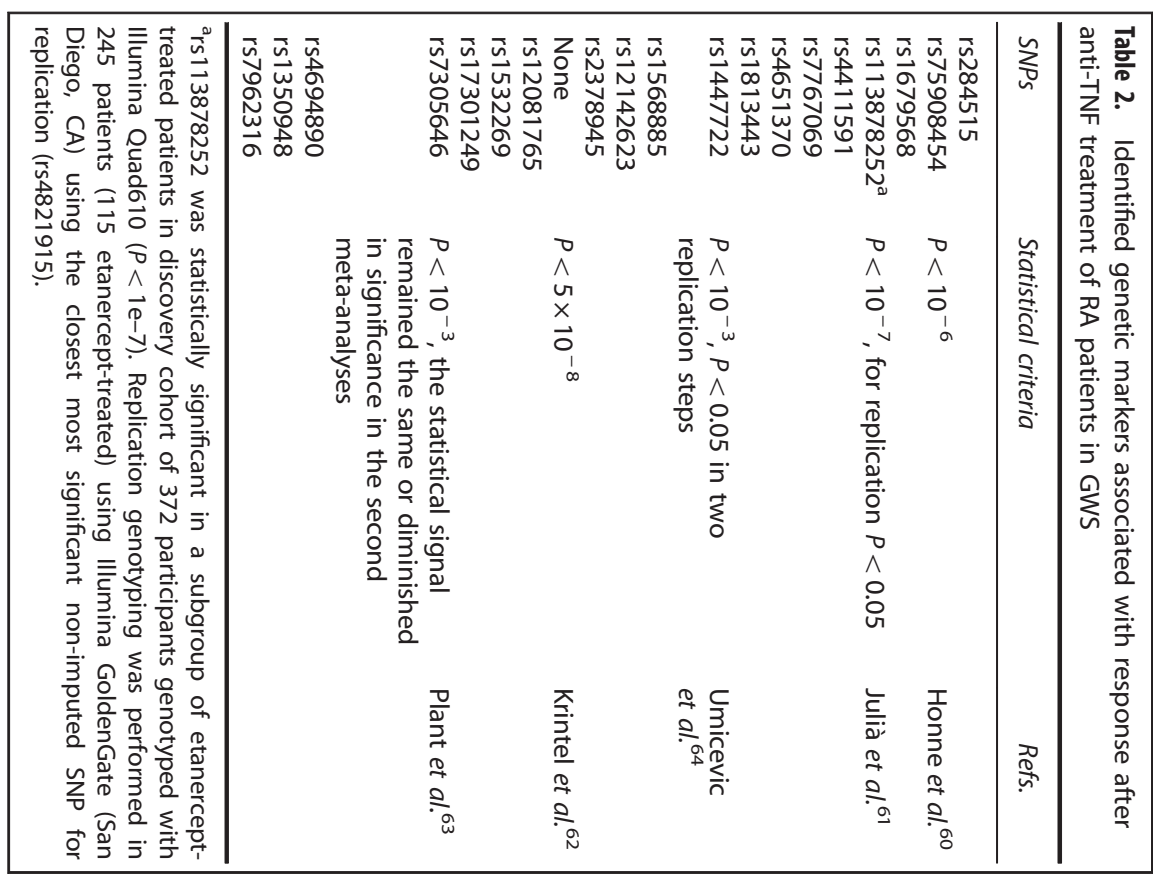

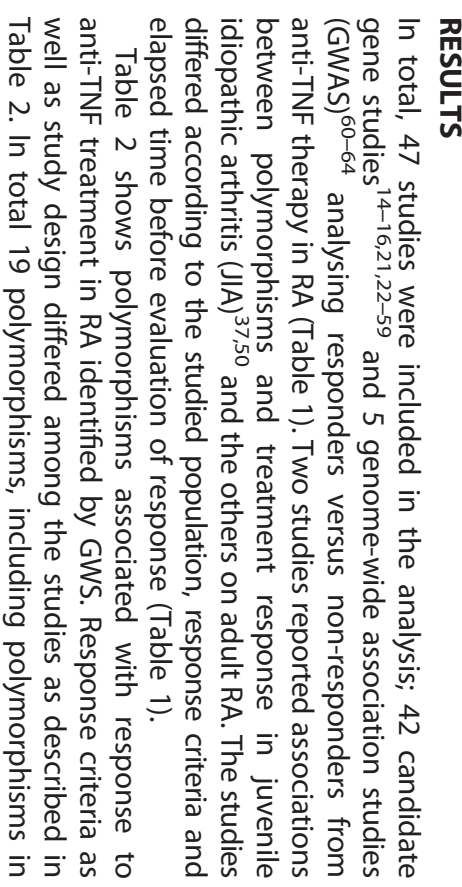

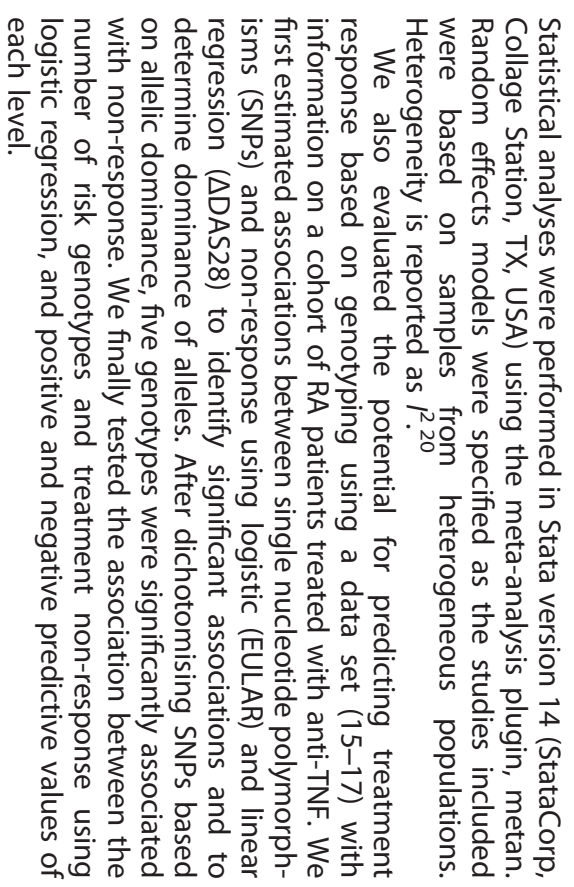




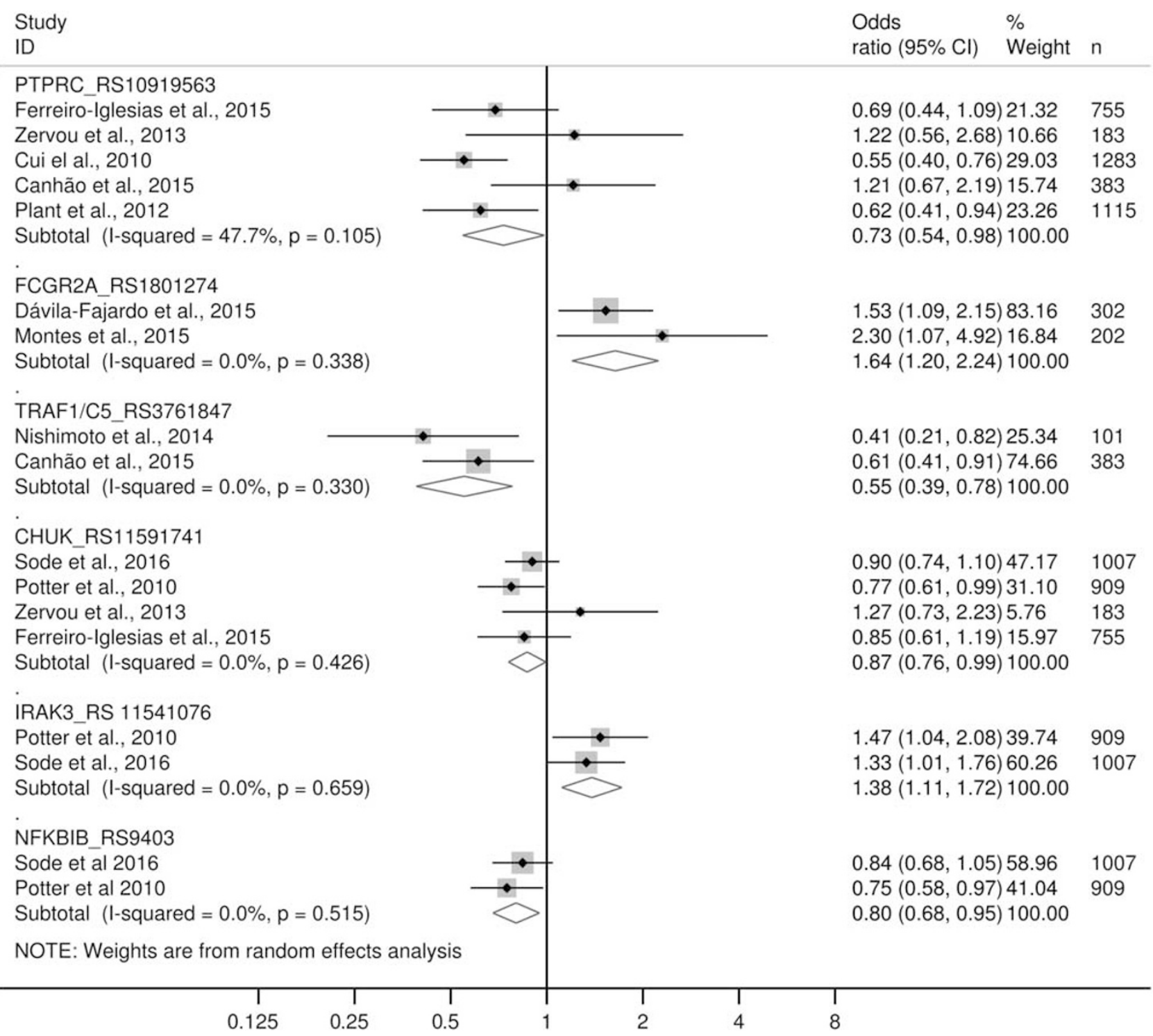

Figure 2. Meta-analyses of 6 polymorphisms in 6 genes, which were associated with treatment response in rheumatoid arthritis (RA).

Table 3. Positive and negative prediction values for selected genotypes in an exploratory analyses based on data from Sode et al. ${ }^{14-16}$

\begin{tabular}{|c|c|c|c|c|c|c|c|}
\hline \multirow[t]{2}{*}{ No. of risk genotypoes } & \multirow[t]{2}{*}{ Response (n) } & \multirow[t]{2}{*}{ Non-response (n) } & \multicolumn{3}{|c|}{ Logistic regression predicting non-response } & \multicolumn{2}{|c|}{ Predictive values } \\
\hline & & & Crude $O R$ & Adj.OR & Adj. 95\% Cl & Pos. & Neg. \\
\hline 1 & 70 & 30 & 2.57 & 3.08 & $(0.83,11.49)$ & 0.7 & 0.3 \\
\hline 2 & 113 & 55 & 2.92 & 3.36 & $(0.93,12.13)$ & 0.67 & 0.33 \\
\hline 3 & 59 & 52 & $5.29 *$ & $6.03^{* *}$ & $(1.65,22.06)$ & 0.53 & 0.47 \\
\hline 4 & 9 & 9 & $6.00 *$ & $6.35^{*}$ & $(1.32,30.48)$ & 0.5 & 0.5 \\
\hline
\end{tabular}

$N=418$. Non-response versus full or partial response. Adjusted for: gender, DAS28, HAQ and DMARD status at baseline. Risk genotypes: CHUK rs 11591741 (CC), IKBKB rs11986055 (CC), IFNGR2 rs17882748 (CT/TT), IL6 rs10499563 (CT/TT), NLRP3 rs4612666 (CT/TT). *P<0.05, ${ }^{* * P}<0.01$. Data from Sode et al. ${ }^{14-16}$

WDR27, GFRA1, MED15, LINC01387, LOC102723883, CNTN5, NUBPL, PDZD2, EYA4, TEC and C12orf79 were identified.

The polymorphisms investigated in candidate gene studies in relation to the outcome from anti-TNF treatment of patients with RA and JIA are shown in Supplementary Table 2. Hundreds of polymorphisms in various pathways have been selected for evaluation as candidate genes. Many of the assessed polymorphisms were found to be associated with response after anti-TNF treatment in one study. However, only few of these polymorphisms have been sought replicated in other candidate gene studies.

Supplementary Table 3 shows the ORs and $95 \% \mathrm{Cl}$ for the associations between polymorphism and treatment response for 
Table 4. Proposed functions of selected polymorphisms that are identified in GWS or meta-analysis as associated with treatment response in RA

\begin{tabular}{|c|c|c|c|c|}
\hline SNPS & Gene & MAF & Allele & Proposed function of genes/proteins and SNPs associated with treatment response in RA \\
\hline rs3761847 & TRAF1 & 0.46 & G & $\begin{array}{l}\text { Gene/protein function: This protein and TRAF2 form a heterodimeric complex, which is required for } \\
\text { TNF-alpha-mediated activation of MAPK8/JNK and NF-kappaB } \\
\text { SNP function: rs } 3761847 \text { is associated with changes in mRNA levels. However, the direction of the } \\
\text { effect differs between tissue types (GTEx, http://www.gtexportal.org.). Furthermore, rs3761847GG } \\
\text { homozygotes have higher Gp210 autoantibody as compared with AA homozygotes. In contrast, } \\
\text { rs3761847AA homozygotes have higher antichromatin as compared to GG homozygotes. }{ }^{66} \text { In } \\
\text { addition, rs3761847GG homozygotes increases the risk of death in RA and appears to be } \\
\text { independent of RA activity and severity as well as comorbidities relevant to cardiovascular disease }\end{array}$ \\
\hline rs4612666 & NLRP3 & 0.41 & $\mathrm{~T}$ & $\begin{array}{l}\text { Gene/protein function: A member of the NALP3 inflammasome complex. This complex functions as } \\
\text { an upstream activator of NF-kappaB signalling, and it has a role in the regulation of inflammation, } \\
\text { the immune response and apoptosis } \\
\text { SNP function: rs } 4612666 \mathrm{~T} \text { decreases expression }{ }^{68}\end{array}$ \\
\hline rs9403 & NFKBIB & 0.45 & C & $\begin{array}{l}\text { Gene/protein function: Inhibit NF-kappa-B by complexing with, and trapping it in the cytoplasm } \\
\text { SNP function: rs9403 is associated with changes in mRNA levels. However, the direction of the effect } \\
\text { differs between tissue types (GTEx, http://www.gtexportal.org.) }\end{array}$ \\
\hline rs1061622 & TNFRSF1B & 0.19 & G & $\begin{array}{l}\text { Gene/protein function: The protein encoded by this gene is thought to potentiate TNF-induced } \\
\text { apoptosis by the ubiquitination and degradation of TNF-receptor-associated factor 2, which } \\
\text { mediates anti-apoptotic signals } \\
\text { SNP function: Unknown }\end{array}$ \\
\hline rs1801274 & FCGR2A & 0.44 & G & 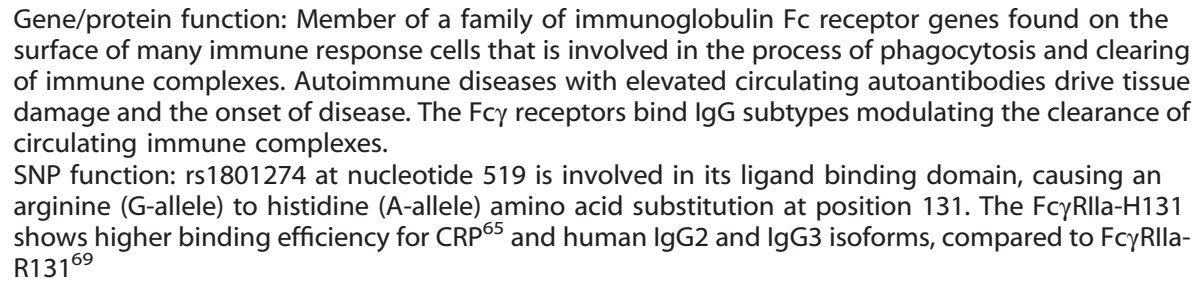 \\
\hline
\end{tabular}

Abbreviation: CRP, C-reactive protein.

polymorphisms that were significantly associated with response in more than one cohort. In total, 23 polymorphisms in 21 genes were identified. These polymorphisms were selected for metaanalyses. Figure 2 shows the results for 6 polymorphisms in 6 genes (CHUK, PTPRC, TRAF1/C5, NFKBIB, FCGR2A and IRAK3) that were associated with treatment response in our meta-analyses. Supplementary Figure 1 shows the results for 17 polymorphisms in 16 genes (including FCGR3A, TNF, CD226, MAPKAPKA, RPS6KA5, MAP2K6, TLR5, TLR1, IFNG, IKBKB and TLR10) that were not associated with treatment response.

Next, to evaluate the current status of clinical use of the biomarkers we perform an explorative analysis of one cohort with available genotyping data. ${ }^{14-16}$ First, we used logistic regression to identify genotypes associated with non-response (risk genotypes) (CHUK rs11591741 (CC), IKBKB rs11986055 (CC), IFNGR2 rs17882748 (CT/TT), IL6 rs10499563 (CT/TT), NLRP3 rs4612666 (CT/TT)). Next, we calculated the OR and $95 \% \mathrm{Cl}$ based on the number of risk genotypes (Table 3; Supplementary Table 4). OR for non-response increased dose-dependently with the number of risk genotypes carried by the patients. For example, individuals with 4 out of 5 non-response-associated genotypes had an OR of $6.35(95 \% \mathrm{Cl}$ : $1.32-30.48$ ) and a negative predictive value of 0.5 . The reference group of individuals with none of the five risk genotypes had the lowest odds (0.17) for non-response and a positive predictive value of 0.86 (indicating a somewhat higher chance of effective treatment than the first-best average (60-70\%)).

\section{DISCUSSION}

We identified polymorphisms associated with treatment outcome from anti-TNF treatment in RA patients from 47 studies with available data (Table 1). Among the 25 polymorphisms that were identified, 19 polymorphisms were found in GWS (Table 2). Our meta-analyses further identified 6 polymorphisms in 6 genes (Figure 2). Furthermore, we analysed the potential predictive power in an exploratory analysis of an available cohort. ${ }^{14-16}$ We found increasing OR for carrying increasing numbers of nonresponse associated polymorphisms (Table 3; Supplementary Table 4). However, the positive and negative predictive values were moderate.

Knowledge on the biological pathways involved in the treatment response in RA may allow for development of new treatment strategies. The results suggest that genetic variants in CTCN5, NUBPL, PD2D2, EYA4 and TEC (from the GWS), and CHUK, PTPRC, TRAF1/C5, NFKBIB, FCGR2A and IRAK3 (from our metaanalysis) may be implicated in treatment response to anti-TNF drugs in RA (Tables 2 and 4, Figure 2 and Supplementary Table 5). Some of the polymorphisms may indeed be functional or be linked to functional polymorphisms. Rs3761847 in TRAF1/C5 is associated with changes in mRNA levels. However, the direction of the effect differs between tissue types (GTEx, http://www. gtexportal.org.). Likewise, rs9403 in NFKBIB has been associated with allele-specific mRNA levels with the variant alleles having the highest expression in liver (GTEx, http://www.gtexportal.org.). FCGR2A rs1801274 is also a missense polymorphism resulting in a non-conservative amino acid substitution (His to Arg). The variant receptor has lowered affinity towards CRP. ${ }^{65}$ The lack of associations may suggest that the assessed genes are not of major importance for treatment response provided that the studies had sufficient power and the investigated polymorphisms are functional themselves or linked to functional polymorphisms. Our meta-analyses suggested that FCGR3A, TNF, CD226, MAPKAPKA, RPS6KA5, MAP2K6, TLR5, TLR1, IFNG, IKBKB and TLR10 were not associated with response after anti-TNF treatment in RA (Supplementary Figure 1).

Recently, we performed a review and meta-analysis of genes involved in response to anti-TNF treatment in patients with inflammatory bowel disease (IBD). ${ }^{12}$ SNPs involved in the TLR signalling pathway were found to be associated with anti-TNF treatment response in IBD, thus suggesting a significant role for 
the host-microbial interaction. Thus, different genes have been identified to be involved in RA and IBD treatment response to antiTNF therapy. This may suggest that genes involved in the adaptive immune response may have a larger role in RA than in IBD treatment response to anti-TNF therapy. However, the role of host-microbial interactions in RA is not clear. Patients with active RA were found to have dysbiosis in the gut microbiota that partly resolved after medical treatment. ${ }^{70}$ The reason for this observation and how it may relate to treatment mechanism(s) is not known.

RA is a highly heterogeneous disease in terms of clinical presentation, prognosis and response to treatment. ${ }^{71}$ It is likely that this also applies to the pathogenesis of RA, in fact, studies have shown pronounced heterogeneity in RA synovial tissue of inflammatory cell types and gene expression. ${ }^{72}$ Through an improved discrimination of different RA subsets, SNP associations may prove to be more clinically useful, as they could at least in theory be very important for a certain subgroup while irrelevant for others.

An explorative approach was used when identifying potential candidate biomarkers in order not to overlook relevant candidates. Response criteria varied between the reviewed studies and more than one criterion were used in most studies. Our findings may furthermore be subject to bias from, for example, publication bias and selective reporting within studies. Replication of findings in other cohorts is of major importance in studies of genetic epidemiology. Therefore, replication of the findings in another cohort was chosen as criterion for association in the present review. Furthermore, environmental factors such as nutrition, smoking, lifestyle and other medication may impact genetic susceptibility and treatment outcome. These factors may not have been captured in the present studies.

Further evaluation of pharmacogenetics of anti-TNF treatment response in rheumatoid arthritis including gene-environmental interactions will require large cohorts of well-characterised patients and replication of positive findings in other cohorts. This work necessitates collaboration between researchers, for example, via International Consortia. Investigations of genomics combined with microbiome and mucosa expression profiles in each patient may thus allow us to understand which pathways and cytokines are deregulated in each case. Such knowledge may be utilised to select the best treatment for each patient.

However, at present, the pharmacogenomic basis for stratifying patients according to the expected response to anti-TNF treatment is not yet available.

\section{CONFLICT OF INTEREST}

VA receives compensation as a consultant and an advisory board member for Merck (MSD) and Janssen. The remaining authors declare no conflict of interest.

\section{ACKNOWLEDGMENTS}

We would like to thank Staff at the Libraries, Regional Hospital Viborg and Hospital of Southern Jutland for their help. VA was supported by 'Knud og Edith Eriksens Mindefon'.

\section{REFERENCES}

1 Symmons D, Turner G, Webb R, Asten P, Barrett E, Lunt M et al. The prevalence of rheumatoid arthritis in the United Kingdom: new estimates for a new century. Rheumatology 2002; 41: 793-800.

2 Feldmann M, Maini SR. Role of cytokines in rheumatoid arthritis: an education in pathophysiology and therapeutics. Immunol Rev 2008; 223: 7-19.

3 Bottazzo GF, Pujol-Borrell R, Hanafusa T, Feldmann M. Role of aberrant HLA-DR expression and antigen presentation in induction of endocrine autoimmunity. Lancet 1983; 2: 1115-1119.

4 Londei M, Lamb JR, Bottazzo GF, Feldmann M. Epithelial cells expressing aberrant MHC class II determinants can present antigen to cloned human T cells. Nature 1984; 312: 639-641
5 Pujol-Borrell R, Todd I, Doshi M, Bottazzo GF, Sutton R, Gray D et al. HLA class II induction in human islet cells by interferon-gamma plus tumour necrosis factor or lymphotoxin. Nature 1987; 326: 304-306.

6 Hetland ML, Christensen IJ, Tarp U, Dreyer L, Hansen A, Hansen IT et al. Direct comparison of treatment responses, remission rates, and drug adherence in patients with rheumatoid arthritis treated with adalimumab, etanercept, or infliximab: results from eight years of surveillance of clinical practice in the nationwide Danish DANBIO registry. Arthritis Rheum 2010; 62: 22-32.

7 Smolen JS, Weinblatt ME, van der Heijde D. Efficacy and safety of tabalumab, an anti-B-cell-activating factor monoclonal antibody, in patients with rheumatoid arthritis who had an inadequate response to methotrexate therapy: results from a phase III multicentre, randomised, double-blind study. Ann Rheum Dis 2015; 74: 1567-1570.

8 Smolen JS, Aletaha D, Koeller M, Weisman MH, Emery P. New therapies for treatment of rheumatoid arthritis. Lancet 2007; 370: 1861-1874.

9 Tarnowski M, Paradowska-Gorycka A, Dabrowska-Zamojcin E, Czerewaty M, Sluczanowska-Glabowska S, Pawlik A. The effect of gene polymorphisms on patient responses to rheumatoid arthritis therapy. Expert Opin Drug Metab Toxicol 2016; 12: 41-55.

10 Plant D, Wilson AG, Barton A. Genetic and epigenetic predictors of responsiveness to treatment in RA. Nat Rev Rheumatol 2014; 10: 329-337.

11 Bank S, Andersen PS, Burisch J, Pedersen N, Roug S, Galsgaard J et al. Polymorphisms in the toll-like receptor and the IL-23/IL-17 pathways were associated with susceptibility to inflammatory bowel disease in a Danish cohort. PLOS ONE 2015; 10: e0145302.

12 Bek S, Nielsen JV, Bojesen AB, Franke A, Bank S, Vogel U et al. Systematic review: genetic biomarkers associated with anti-TNF treatment response in inflammatory bowel diseases. Alimen Pharmacol Therap 2016; 44: 554-567.

13 Bank S, Andersen PS, Burisch J, Pedersen N, Roug S, Galsgaard J et al. Associations between functional polymorphisms in the NFkappaB signaling pathway and response to anti-TNF treatment in Danish patients with inflammatory bowel disease. Pharmacogenomics J 2014; 14: 526-534.

14 Sode J, Vogel U, Bank S, Andersen PS, Hetland ML, Locht $\mathrm{H}$ et al. Genetic variation in the TLR5 locus is associated with anti-TNF response among rheumatoid arthritis patients. Arthritis Rheumatol 2014; 66: S1092-S1093.

15 Sode J, Vogel U, Bank S, Andersen PS, Hetland ML, Locht $\mathrm{H}$ et al. Confirmation of an IRAK3 polymorphism as a genetic marker predicting response to anti-TNF treatment in rheumatoid arthritis. Pharmacogenomics J 2016; doi: 10.1038/ tpj.2016.66 [Epub ahead of print].

16 Sode J, Vogel U, Bank S, Andersen PS, Hetland ML, Locht H et al. Genetic variations in pattern recognition receptor loci are associated with anti-TNF response in patients with rheumatoid arthritis. PLOS ONE 2015; 10: e0139781.

17 Weng L, Zhang L, Peng Y, Huang RS. Pharmacogenetics and pharmacogenomics: a bridge to individualized cancer therapy. Pharmacogenomics 2013; 14: 315-324.

18 Moher D, Liberati A, Tetzlaff J, Altman DG. Preferred reporting items for systematic reviews and meta-analyses: the PRISMA statement. PLoS Med 2009; 6: e1000097.

19 Fransen J, van Riel PL. The disease activity score and the EULAR response criteria. Clin Exp Rheumatol 2005; 23: S93-S99.

20 Higgins JP, Thompson SG. Quantifying heterogeneity in a meta-analysis. Stat Med 2002; 21: 1539-1558.

21 Iwaszko M, Swierkot J, Kolossa K, Jeka S, Wiland P, Bogunia-Kubik K. Polymorphisms within the human leucocyte antigen-E gene and their associations with susceptibility to rheumatoid arthritis as well as clinical outcome of antitumour necrosis factor therapy. Clin Exp Immunol 2015; 182: 270-277.

22 Canet LM, Filipescu I, Caliz R, Lupianez CB, Canhao H, Escudero A et al. Genetic variants within the TNFRSF1B gene and susceptibility to rheumatoid arthritis and response to anti-TNF drugs: a multicenter study. Pharmacogenet Genomics 2015; 25: 323-333.

23 Smith SL, Plant D, Lee XH, Massey J, Hyrich K, Morgan AW et al. Previously reported PDE3A-SLCO1C1 genetic variant does not correlate with anti-TNF response in a large UK rheumatoid arthritis cohort. Pharmacogenomics 2016; 17: 715-720.

24 Iwaszko M, Swierkot J, Kolossa K, Jeka S, Wiland P, Bogunia-Kubik K. Influence of CD94 and NKG2A variants on susceptibility to rheumatoid arthritis and efficacy of anti-TNF treatment. Joint Bone Spine Revue du Rhumatisme 2016; 83: 75-79.

25 Marquez A, Ferreiro-Iglesias A, Davila-Fajardo CL, Montes A, Pascual-Salcedo D, Perez-Pampin E et al. Lack of validation of genetic variants associated with antitumor necrosis factor therapy response in rheumatoid arthritis: a genome-wide association study replication and meta-analysis. Arthritis Res Therapy 2014; 16: R66.

26 Bowes JD, Potter C, Gibbons LJ, Hyrich K, Plant D, Morgan AW et al. Investigation of genetic variants within candidate genes of the TNFRSF1B signalling pathway on the response to anti-TNF agents in a UK cohort of rheumatoid arthritis patients. Pharmacogenet Genomics 2009; 19: 319-323.

27 Miceli-Richard C, Comets E, Verstuyft C, Tamouza R, Loiseau P, Ravaud P et al. A single tumour necrosis factor haplotype influences the response to adalimumab in rheumatoid arthritis. Ann Rheum Dis 2008; 67: 478-484. 
28 Ferreiro-Iglesias A, Montes A, Perez-Pampin E, Canete JD, Raya E, Magro-Checa C et al. Replication of PTPRC as genetic biomarker of response to TNF inhibitors in patients with rheumatoid arthritis. Pharmacogenomics J 2015; 16: 137-140.

29 Canet LM, Caliz R, Lupianez CB, Canhao H, Martinez M, Escudero A et al. Genetic variants within immune-modulating genes influence the risk of developing rheumatoid arthritis and anti-TNF drug response: a two-stage case-control study. Pharmacogenet Genomics 2015; 25: 432-443.

30 Ceccarelli F, D'Alfonso S, Perricone C, Carlomagno Y, Alessandri C, Croia C et al. The role of eight polymorphisms in three candidate genes in determining the susceptibility, phenotype, and response to anti-TNF therapy in patients with rheumatoid arthritis. Clin Exp Rheumatol 2012; 30: 939-942.

31 Davila-Fajardo CL, Marquez A, Pascual-Salcedo D, Moreno Ramos MJ, Garcia-Portales R, Magro C et al. Confirmation of $-174 \mathrm{G} / \mathrm{C}$ interleukin- 6 gene promoter polymorphism as a genetic marker predicting antitumor necrosis factor treatment outcome. Pharmacogenet Genomics 2014; 24: 1-5.

32 Davila-Fajardo $C L$, van der Straaten T, Baak-Pablo R, Medarde Caballero C, Cabeza Barrera J, Huizinga TW et al. FcGR genetic polymorphisms and the response to adalimumab in patients with rheumatoid arthritis. Pharmacogenomics 2015; 16: 373-381.

33 Montes A, Perez-Pampin E, Joven B, Carreira P, Fernandez-Nebro A, Del Carmen Ordonez $M$ et al. FCGR polymorphisms in the treatment of rheumatoid arthritis with Fc-containing TNF inhibitors. Pharmacogenomics 2015; 16: 333-345.

34 Nishimoto T, Seta N, Anan R, Yamamoto T, Kaneko Y, Takeuchi T et al. A single nucleotide polymorphism of TRAF1 predicts the clinical response to anti-TNF treatment in Japanese patients with rheumatoid arthritis. Clin Exp Rheumatol 2014; 32: 211-217.

35 Pinto JA, Rego I, Rodriguez-Gomez M, Canete JD, Fernandez-Lopez C, Freire M et al. Polymorphisms in genes encoding tumor necrosis factor-alpha and HLADRB1 are not associated with response to infliximab in patients with rheumatoid arthritis. J Rheumatol 2008; 35: 177-178.

36 Potter C, Gibbons U, Bowes JD, Cordell HJ, Hyrich K, Isaacs JD et al. Polymorphisms spanning the TNFR2 and TACE genes do not contribute towards variable anti-TNF treatment response. Pharmacogenet Genomics 2010; 20: 338-341.

37 Cimaz R, Cazalis MA, Reynaud C, Gerloni V, Zulian F, Biggioggero M et al. IL1 and TNF gene polymorphisms in patients with juvenile idiopathic arthritis treated with TNF inhibitors. Ann Rheum Dis 2007; 66: 900-904.

38 Coenen MJ, Enevold C, Barrera P, Schijvenaars MM, Toonen EJ, Scheffer $\mathrm{H}$ et al. Genetic variants in toll-like receptors are not associated with rheumatoid arthritis susceptibility or anti-tumour necrosis factor treatment outcome. PLOS ONE 2010; 5: e14326.

39 Coulthard LR, Taylor JC, Eyre S, Biologics in Rheumatoid Arthritis Genetics and Genomics, Robinson J, Wilson AG. Genetic variants within the MAP kinase signalling network and anti-TNF treatment response in rheumatoid arthritis patients. Ann Rheum Diseases 2011; 70: 98-103.

40 Cui J, Saevarsdottir S, Thomson B, Padyukov L, van der Helm-van Mil AH, Nititham $\mathrm{J}$ et al. Rheumatoid arthritis risk allele PTPRC is also associated with response to anti-tumor necrosis factor alpha therapy. Arthritis Rheum 2010; 62: 1849-1861.

41 Hassan B, Maxwell JR, Hyrich KL, Biologics in Rheumatoid Arthritis Genetics and Genomics Study Syndicate, Barton A, Worthington J. Genotype at the sIL-6R A358C polymorphism does not influence response to anti-TNF therapy in patients with rheumatoid arthritis. Rheumatology 2010; 49: 43-47.

42 Kastbom A, Bratt J, Ernestam S, Lampa J, Padyukov L, Soderkvist P et al. Fcgamma receptor type IIIA genotype and response to tumor necrosis factor alpha-blocking agents in patients with rheumatoid arthritis. Arthritis Rheum 2007; 56: 448-452.

43 Marotte H, Pallot-Prades B, Grange L, Tebib J, Gaudin P, Alexandre C et al. The shared epitope is a marker of severity associated with selection for, but not with response to, infliximab in a large rheumatoid arthritis population. Ann Rheum Dis 2006; 65: 342-347.

44 Mathews RJ, Robinson Jl, Battellino M, Wong C, Taylor JC, Biologics in Rheumatoid, Arthritis $\mathrm{G}$ et al. Evidence of NLRP3-inflammasome activation in rheumatoid arthritis (RA); genetic variants within the NLRP3-inflammasome complex in relation to susceptibility to RA and response to anti-TNF treatment. Ann Rheum Dis 2014; 73: 1202-1210.

45 Ongaro A, De Mattei M, Pellati A, Caruso A, Ferretti S, Masieri FF et al. Can tumor necrosis factor receptor II gene $676 \mathrm{~T}>\mathrm{G}$ polymorphism predict the response grading to anti-TNFalpha therapy in rheumatoid arthritis? Rheumatol Int 2008; 28: 901-908.

46 Padyukov L, Lampa J, Heimburger M, Ernestam S, Cederholm T, Lundkvist I et al. Genetic markers for the efficacy of tumour necrosis factor blocking therapy in rheumatoid arthritis. Ann Rheum Dis 2003; 62: 526-529.

47 Plant D, Prajapati R, Hyrich KL, Morgan AW, Wilson AG, Isaacs JD et al. Replication of association of the PTPRC gene with response to anti-tumor necrosis factor therapy in a large UK cohort. Arthritis Rheum 2012; 64: 665-670.
48 Potter C, Cordell HJ, Barton A, Daly AK, Hyrich KL, Mann DA et al. Association between anti-tumour necrosis factor treatment response and genetic variants within the TLR and NF\{kappa\}B signalling pathways. Ann Rheum Dis 2010; 69: 1315-1320.

49 Potter C, Hyrich KL, Tracey A, Lunt M, Plant D, Symmons DP et al. Association of rheumatoid factor and anti-cyclic citrullinated peptide positivity, but not carriage of shared epitope or PTPN22 susceptibility variants, with anti-tumour necrosis factor response in rheumatoid arthritis. Ann Rheumatic Dis 2009; 68: 69-74.

50 Schmeling $\mathrm{H}$, Horneff $\mathrm{G}$. Tumour necrosis factor alpha promoter polymorphisms and etanercept therapy in juvenile idiopathic arthritis. Rheumatol Int 2007; 27: 383-386.

51 Suarez-Gestal M, Perez-Pampin E, Calaza M, Gomez-Reino JJ, Gonzalez A. Lack of replication of genetic predictors for the rheumatoid arthritis response to anti-TNF treatments: a prospective case-only study. Arthritis Res Therapy 2010; 12: R72.

52 Swierkot J, Bogunia-Kubik K, Nowak B, Bialowas K, Korman L, Gebura K et al. Analysis of associations between polymorphisms within genes coding for tumour necrosis factor (TNF)-alpha and TNF receptors and responsiveness to TNF-alpha blockers in patients with rheumatoid arthritis. Joint Bone Spine Revue du Rhumatisme 2015; 82: 94-99.

53 Tan RJ, Gibbons L, Potter C, Hyrich KL, Morgan AW, Wilson AG et al. Investigation of rheumatoid arthritis susceptibility genes identifies association of AFF3 and CD226 variants with response to anti-tumour necrosis factor treatment. Ann Rheum Dis 2010; 69: 1029-1035.

54 Toonen EJ, Coenen MJ, Kievit W, Fransen J, Eijsbouts AM, Scheffer $\mathrm{H}$ et al. The tumour necrosis factor receptor superfamily member $1 \mathrm{~b} 676 \mathrm{~T}>\mathrm{G}$ polymorphism in relation to response to infliximab and adalimumab treatment and disease severity in rheumatoid arthritis. Ann Rheum Dis 2008; 67: 1174-1177.

55 Zervou MI, Myrthianou E, Flouri I, Plant D, Chlouverakis G, Castro-Giner F et al. Lack of association of variants previously associated with anti-TNF medication response in rheumatoid arthritis patients: results from a homogeneous Greek population. PLOS ONE 2013; 8: e74375.

56 Montes A, Perez-Pampin E, Narvaez J, Canete JD, Navarro-Sarabia F, Moreira V et al. Association of FCGR2A with the response to infliximab treatment of patients with rheumatoid arthritis. Pharmacogenet Genomics 2014; 24: 238-245.

57 Maxwell JR, Potter C, Hyrich KL, Biologics in Rheumatoid Arthritis Genetics and Genomics Study Syndicate, Barton A et al. Association of the tumour necrosis factor-308 variant with differential response to anti-TNF agents in the treatment of rheumatoid arthritis. Hum Mol Genet 2008; 17: 3532-3538.

58 Canhao H, Rodrigues AM, Santos MJ, Carmona-Fernandes D, Bettencourt BF, Cui J et al. TRAF1/C5 but not PTPRC variants are potential predictors of rheumatoid arthritis response to anti-tumor necrosis factor therapy. BioMed Res Int 2015; 2015: 490295 .

59 Acosta-Colman I, Palau N, Tornero J, Fernandez-Nebro A, Blanco F, GonzalezAlvaro I et al. GWAS replication study confirms the association of PDE3A-SLCO1C1 with anti-TNF therapy response in rheumatoid arthritis. Pharmacogenomics 2013; 14: 727-734.

60 Honne K, Hallgrimsdottir I, Wu C, Sebro R, Jewell NP, Sakurai T et al. A longitudinal genome-wide association study of anti-tumor necrosis factor response among Japanese patients with rheumatoid arthritis. Arthritis Res Therapy 2016; 18: 12.

61 Julia A, Fernandez-Nebro A, Blanco F, Ortiz A, Canete JD, Maymo J et al. A genome-wide association study identifies a new locus associated with the response to anti-TNF therapy in rheumatoid arthritis. Pharmacogenomics J 2015; 16: 147-150.

62 Krintel SB, Palermo G, Johansen JS, Germer S, Essioux L, Benayed R et al. Investigation of single nucleotide polymorphisms and biological pathways associated with response to TNFalpha inhibitors in patients with rheumatoid arthritis. Pharmacogenet Genomics 2012; 22: 577-589.

63 Plant D, Bowes J, Potter C, Hyrich KL, Morgan AW, Wilson AG et al. Genome-wide association study of genetic predictors of anti-tumor necrosis factor treatment efficacy in rheumatoid arthritis identifies associations with polymorphisms at seven loci. Arthritis Rheum 2011; 63: 645-653.

64 Umicevic Mirkov M, Cui J, Vermeulen SH, Stahl EA, Toonen EJ, Makkinje RR et al. Genome-wide association analysis of anti-TNF drug response in patients with rheumatoid arthritis. Ann Rheum Dis 2013; 72: 1375-1381.

65 Stein MP, Edberg JC, Kimberly RP, Mangan EK, Bharadwaj D, Mold C et al. Creactive protein binding to FcgammaRlla on human monocytes and neutrophils is allele-specific. J Clin Invest 2000; 105: 369-376.

66 Kempinska-Podhorodecka A, Shums Z, Wasilewicz M, Wunsch E, Milkiewicz M, Bogdanos DP et al. TRAF1 gene polymorphism correlates with the titre of Gp210 antibody in patients with primary biliary cirrhosis. Clin Dev Immunol 2012; 2012: 487521.

67 Panoulas VF, Smith JP, Nightingale P, Kitas GD. Association of the TRAF1/C5 locus with increased mortality, particularly from malignancy or sepsis, in patients with rheumatoid arthritis. Arthritis Rheum 2009; 60: 39-46. 
68 Hitomi Y, Ebisawa M, Tomikawa M, Imai T, Komata T, Hirota T et al. Associations of functional NLRP3 polymorphisms with susceptibility to food-induced anaphylaxis and aspirin-induced asthma. J Allergy Clin Immunol 2009; 124: 779-785e776.

69 Lopez-Escamez JA, Saenz-Lopez P, Gazquez I, Moreno A, Gonzalez-Oller C, Soto-Varela A et al. Polymorphisms of CD16A and CD32 Fcgamma receptors and circulating immune complexes in Meniere's disease: a case-control study. BMC Med Genet 2011; 12: 2.

70 Zhang X, Zhang D, Jia H, Feng Q, Wang D, Liang D et al. The oral and gut microbiomes are perturbed in rheumatoid arthritis and partly normalized after treatment. Nat Med 2015; 21: 895-905.

71 van der Pouw Kraan TC, van Gaalen FA, Kasperkovitz PV, Verbeet NL, Smeets TJ, Kraan MC et al. Rheumatoid arthritis is a heterogeneous disease: evidence for differences in the activation of the STAT-1 pathway between rheumatoid tissues. Arthritis Rheum 2003; 48: 2132-2145.
72 Dennis G Jr., Holweg CT, Kummerfeld SK, Choy DF, Setiadi AF, Hackney JA et al. Synovial phenotypes in rheumatoid arthritis correlate with response to biologic therapeutics. Arthritis Res therapy 2014; 16: R90.

(1) This work is licensed under a Creative Commons AttributionBY NC SA NonCommercial-ShareAlike 4.0 International License. The images or other third party material in this article are included in the article's Creative Commons license, unless indicated otherwise in the credit line; if the material is not included under the Creative Commons license, users will need to obtain permission from the license holder to reproduce the material. To view a copy of this license, visit http:// creativecommons.org/licenses/by-nc-sa/4.0/

(c) The Author(s) 2017

Supplementary Information accompanies the paper on the The Pharmacogenomics Journal website (http://www.nature.com/tpj) 